\title{
Standard Reference Materials of Microanalysis in China
}

\author{
Zhenyu Chen ${ }^{1 *}$, Jianxiong Zhou ${ }^{1}$ \\ 1. Institute of Mineral Resources, Chinese Academy of Geological Sciences \\ * Corresponding author: chenzhenyu@cags.ac.cn
}

Electron probe microanalyzers (EPMA) were first introduced in China in 1965 in some research institutes related to geology, mining, metallurgy, and materials science in Beijing and Guilin. At that time, all the standard reference materials (SRMs) used in EPMA labs, even quartz and hematite, were obtained from the EPMA manufacturers or the C. M. Taylor Company in the United States [1]. Due to the limited availability of the imported SRMs and the installations of additional EPMA in China, some EPMA and SEM with EDS labs began developing their own SRMs from 1970s. For example, dozens of minerals and rare earth oxides were selected and used as SRMs for EPMA by some labs [2]. However, these self-developed SRMs were not well characterized, thus not widely adopted by other labs. In addition, there was no common understanding on the technical specifications of the SRMs [1,2].

In 1981, during the First Meeting on the Application of Microbeam Analysis in Geology, an initiative was proposed to start a work group, affiliated with Chinese Society of Electron Microscopy and Chinese Society of Mineralogy Petrology and Geochemistry, to define technical specifications of a SRM and develop SRMs [3]. In 1984, the China National Technical Committee of Microbeam Analysis Standard Standardization (CNTCMASS) was established under China State Bureau of Standard to examine and certify SRMs for EPMA. From 1981 to 1985, 56 SRMs, including 36 natural minerals and 20 synthetic materials, were developed collectively by sixteen EPMA and SEM labs within the Chinese Academy of Geological Sciences, with funding from the Ministry of Geology and Mineral Resources. These SRMs were approved by China State Bureau of Metrology and each was assigned a number preceded with GBW (short for Chinese Pinyin Guojia Biaozhun Wuzhi), meaning national standard material [4]. In 1987, 19 National Standard Specimens of EPMA developed by CNTCMASS were approved by China State Bureau of Standard and each was assigned a number preceded with GSB (short for Chinese Pinyin Guojia Shiwu Biaozhun), meaning national physical standard. In the meanwhile, CNTCMASS also recommended 40 research standard specimens numbered with MAS (Microbeam Analysis Standard) approved by CNTCMASS for EPMA labs, including metals, alloys, synthetic rare element oxides and natural minerals [5].

In 1985, "General Specification of Electron Probe Microanalysis Standard Specimen” prepared by CNTCMASS was published as a China National Standard GB/T4930-85, which specified material preparation, homogeneity, stability, certification, packaging and storage, and period of validity of SRMs and was thought to be the first national standard on SRMs for EPMA in the international microanalysis community [3]. By the end of 1997, more than 250 SRMs were developed by following the requirements of GB/T4930-85. These SRMs were later published by CNTCMASS as an appendix in the China National Standard "General specification of X-ray EDS quantitative analysis for EPMA and SEM" (GB/T17359-98) in 1998 (Table 1). Among them, common mineral standards include GSB A70014 rhodonite $(\mathrm{Mn}, \mathrm{Fe}, \mathrm{Ca}) \mathrm{SiO}_{3}, \mathrm{GSB}$ A70015 wollastonite $\mathrm{CaSiO}_{3}, \mathrm{GSB}$ A70017 scheelite $\mathrm{CaWO}_{4}$, GSB A70020 enstatite $\mathrm{MgSiO}_{3}$, GSB A70021 pyrope $\mathrm{Mg}_{3} \mathrm{Al}_{2}\left(\mathrm{SiO}_{4}\right)_{3}$, GSB A70022 pyrite FeS 2 , GSB D33002 chromite $\mathrm{FeCrO}_{4}$, GSB D53002 diopside (CaMg)SiO 3 , etc. 
In 1991, the Technical Committee of Microbeam Analysis, proposed by CNTCMASS, was established in China by the International Organization for Standardization (ISO/TC202) [6]. CNTCMASS was later renamed as China National Technical Committee of Microbeam Analysis under China State Bureau of Technical Supervision, responsible for establishment of national standards and certification of SRMs for microbeam analysis [2, 6]. In 1993, the previously published GB/T4930-85 was revised and published as GB/T4930-93 and its English version was proposed to ISO/TC202's Electron Probe Microanalysis Subcommittee (ISO/TC202/SC2) as a draft for international standard. With revisions from the experts from members of ISO/TC202, the international standard "Microbeam Analysis -Electron Probe Microanalysis - Guidelines for the Specification of Certified Reference Materials (CRMs)" was officially published in 2003 as ISO14595:2003 [2, 6], which was later revised as ISO14595:2014 in 2014. This international standard provides guidelines on selection of SRMs, determination of the chemical composition of SRMs, evaluation of heterogeneity and stability of SRMs.

The number of EPMA in China has been increasing rapidly during the last decade, there are more than 150 EPMA in use in China currently, and each year additional 10 15 EPMA are installed. More than 90\% of the SRMs used in the EPMA labs in China were developed within China under the guidance of national standard and international standard [7].

\section{References:}

[1] Liu Yongkang, Journal of electron microscopy Vol 1 (1987), p. 1-7.

[2] Zhuang Shijie, Proceedings of Annual meeting of Microbeam Analysis in China (2004) p. 21-30.

[3] Zhang Yi, Journal of electron microscopy Vol 1 (1987), p. 16-21.

[4] Jin Binghui, Rock and Mineral Analysis Vol 5 (1986), p. 157-163.

[5] Lin Zhuoran, Journal of electron microscopy Vol 1 (1987), p. 8-15.

[6] Zeng Rongshu, Proceedings of Annual meeting of Microbeam Analysis in China (2004) p. 1-7.

[7] The authors acknowledge Drs. Donggao Zhao and John Donovan for their thoughtful comments and revision.

Table 1. Types of SRMs listed in China National Standard GB/T17359-98 for EPMA and SEM

\begin{tabular}{|l|c|}
\hline Types of SRMs for EPMA and SEM & Number of SRMs \\
\hline Metal and alloy (including 40 simple metal and 53 alloys) & 63 \\
\hline Oxide (including simple oxide and complex oxide) & 17 \\
\hline Sulfide (natural minerals and synthetic materials) & 42 \\
\hline Silicate (along with a few phosphates, sulphates and carbonate) & 19 \\
\hline Rare earth pentaphosphate and boride (synthetic single crystals) & 28 \\
\hline Light element, semiconductor and others (simple substance and compound) & \\
\hline
\end{tabular}

